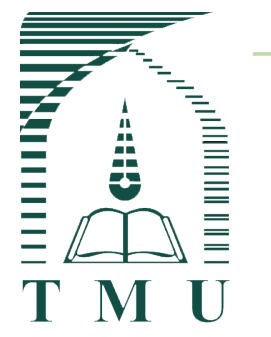

\title{
In Vitro Evaluation of Antibacterial and Antifungal Properties of Some New 1, 3, 4-0xadiazole Derivatives Containing Phenyl Group
}

\section{A R T I C L E I N F O}

\section{Article Type}

Original Research

\section{Authors}

Nakisa Zarrabi Ahrabi, $P h D^{1}$

Ali Souldozi, $P h D^{2}$

Yasin SarveAhrabi, $M S c^{3^{*}}$

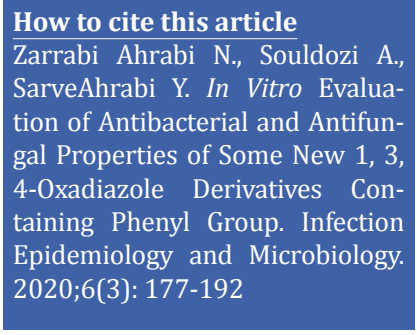

1 Department of Biology, Central Tehran Branch, Islamic Azad University, Tehran, Iran

${ }^{2}$ Department of Chemistry, Urmia Branch, Islamic Azad University, Urmia, Iran

3 Department of Biology, Central Tehran Branch, Islamic Azad University, Tehran, Iran

\section{* Correspondence}

Address: PhD Student of Microbiology, Department of Biology, Central Tehran Branch, Islamic Azad University, Tehran, Iran. yasin.ahrabi2016@gmail.com

\section{Article History}

Received: June 15,2020

Accepted: July 25,2020

Published: August 15,2020

\section{A B S T R A C T}

Aims: Antibiotic resistance is recognized as one of the most challenging public health problems in the world. The need for new antibacterial and antifungal drugs is justified because many pathogens are currently resistant to available drugs. Several components of 1 , 3, 4-oxadiazoles have been shown to pose a wide range of antibacterial activities.

Materials \& Methods: The new derivatives of 1, 3, 4-oxadiazole were synthesized using a single-stage method. The structure of derivatives was evaluated by IR, H-NMR, C-NMR, and GC-Mass methods. Then to measure the antibacterial and antifungal activities of the prepared derivatives at a concentration of $0.5 \mathrm{mg} / \mathrm{mL}$, agar well diffusion method was employed, and the minimum inhibitory concentration (MIC) and the minimum bactericidal/fungicidal concentration (MBC/MFC) were determined with three replications.

Findings: The study of antibacterial properties of the prepared derivatives showed the highest activity of the compounds $4 \mathrm{~b}$-g against Enterococcus faecalis strains, among which the compound $4 \mathrm{~g}$ with $\mathrm{IZ}=55.66 \pm 0.5 \mathrm{~mm}$ and $\mathrm{MIC}=31.25 \mathrm{mg} / \mathrm{mL}$ had the greatest effect compared to the others. Also, the compound $4 \mathrm{f}$ with $\mathrm{MIC}=125 \mathrm{mg} / \mathrm{mL}$ had a powerful effect against $E$. faecalis strains. In the case of fungal samples, the highest activity of the compound $4 \mathrm{~b}$ was with $\mathrm{IZ}=12.33 \pm 0.5 \mathrm{~mm}$ against Candida glabrata and with $\mathrm{IZ}=13.33 \pm 0.5 \mathrm{~mm}$ against C. krusei strains.

Conclusion: The new 1, 3, 4-oxadiazole derivatives (4b, 4d, and 4g) with tolyl, dimetylphenyl, and methoxyphenyl groups were shown to be a promising compounds for pharmaceutical applications so that by adding other functional groups to their structure, it is possible to increase the destructive power of these compounds.

\section{Keywords: Oxadiazole, Enterococcus faecalis, Drug resistance.}

\section{CITATION LINKS}

[1] White NJ. Antimalarial drug resistance. J Clin Invest... [2] Antony HA, Parija SC. Antimalarial drug... [3] Lemos JA, Palmer SR, Zeng L, Wen ZT, Kajfasz JK, Freires IA, et al. The biology of Streptococcus mutans. In: Fischetti VA, Novick RP, Ferretti JJ, Portnoy DA, Braunstein M, Rood JI, editors... [4] Jafri H, Khan MS, Ahmad I. In vitro efficacy of eugenol in inhibiting single and... [5] Dahl A, Iversen K, Tonder N, Hoest N, Arpi M, Dalsgaard M, et al. Prevalence of infective endocarditis in... [6] Davis E, Hicks L, Ali I, Salzman E, Wang J, Snitkin E, et al. Epidemiology of ... [7] Keppler-Noreuil KM, Sapp JC, Lindhurst MJ, Darling TN, Burton-Akright J, Bagheri M, et al. Pharmacodynamic ... [8] Bontron S, Poirel L, Kieffer N, Savov E, Trifonova A, Todorova I, et al. Increased resistance to ... [9] Caugant DA, Brynildsrud OB. Neisseria meningitidis: Using genomics to understand diversity, evolution, and ... [10] McNamara LA, Potts C, Blain AE, Retchless AC, Reese N, Swint S, et al. Detection of ... [11] Kullberg BJ, Viscoli C, Pappas PG, Vazquez J, Ostrosky-Zeichner L, Rotstein C, et al. Isavuconazole ... [12] Yeh SJ, Yeh CC, Lan CY, Chen BS. Investigating common pathogenic mechanisms between homo sapiens and ... [13] Pristov KE, Ghannoum MA. Resistance of Candida to azoles and ... [14] Sarveahrabi Y, Souldozi A, Talebi R. 2-Substituent synthesis of ... [15] Bitla S, Sagurthi SR, Dhanavath R, Reddy PM, Birudaraju S, Gayatri AA, et al. Design and synthesis of triazole conjugated novel 2, 5-diaryl substituted 1, 3, 4-oxadiazoles as ... [16] Maslat AO, Abussaud M, Tashtoush H, AL-Talib M. Synthesis, antibacterial, antifungal, and ...[17] Ahsan MJ, Choupra A, Sharma RK, Jadav SS, Padmaja P, Hassan M, et al. Rationale design, synthesis, cytotoxicity evaluation, and ...[18] Bhaumik A, Eswaraiah MC, Chakraborty R. Evaluation of ... [19] SarveAhrabi Y, Souldozi A, Zarrabi Ahrabi N. In vitro ... [20] Rohand T, Ramli Y, Baruah M, Budka J, Das AM. Synthesis, structure ... [21] Shi J, Luo N, Ding M, Bao X. Synthesis, in vitro... [22] Souldozi A, Karami S. One-pot three-component reaction for the synthesis of novel series of... [23] Clinical and Laboratory Standards Institute. Supplement... [24] Lee WB, Fu CY, Chang WH, You HL, Wang CH, Lee MS, et al. A microfluidic... [25] Lushniak BD. Antibiotic resistance: A public health... [26] Othman AA, Kihel M, Amara S. 1, 3, 4-oxadiazole, 1, 3, 4-thiadiazole, and...[27] Aghekyan AA, Mkryan GG, Panosyan HA, Safaryan AS, Stepanyan HM. Synthesis and ... [28] Guo Y, Xu T, Bao C, Liu Z, Fan J, Yang R, et al. Design and ... [29] Tresse C, Radigue R, Von Borowski RG, Thepaut M, Le HH, Demay F, et al. Synthesis and... . 


\section{Introduction}

The trend of drug resistance in bacteria and fungi has been growing in recent decades, and the first case of drug resistance was reported in $1947^{[1]}$. Antibiotic resistance is a type of drug resistance in which diseasecausing microorganisms (bacteria, fungi, etc.) do not respond to antibiotic treatment [2]. The Streptococcaceae family members, especially $S$. mutans species which is a Grampositive bacterium in the mouth, create an acidic environment by metabolizing various carbohydrates; Extracellular glucan formation is the main cause of pathogenicity of this bacterium and the cause of dental caries in humans and animals ${ }^{[3]}$. Nowadays, there are many reports about the relative resistance of normal oral microflora, especially streptococci, to biocides and antibiotics like beta lactam, penicillin, erythromycin, macrolides, and tetracycline [4]. The Enterococcus family members, including E. faecalis which is a Gram-positive bacterium, have been identified as major causative agents of infections, especially nosocomial infections, and the epidemiology of enterococci infections has received considerable attention. These bacteria are known as the fourth leading cause of nosocomial infections, the third leading cause of bacteremia infections, and the second leading cause of urinary tract infections [5]. Various studies have shown antibiotic resistance of this bacterial species ${ }^{[6]}$. Proteus bacilli are also optional Gram-negative bacilli belonging to the group of Proteobacteria and aerobic anaerobes ${ }^{[7]}$. Proteus in humans sometimes causes urinary tract and wound infections. Today, there are numerous reports about the resistance of this group of bacteria to ampicillin and cephalosporins ${ }^{\left[{ }^{8]} \text {. Neisseria }\right.}$ meningitidis or meningococcus is a bacterium causing meningitis. This bacterium could also cause meningococcemia (infection of the blood). Meningococcus is one of the leading causes of death in children in developed countries, sometime causing epidemics in Asia and Africa. Rifampin is the drug of choice for the treatment of infections caused by this bacterium, but its use may be harmful [9] because there are several reports about antibiotic resistance after treatment [10]. Candida yeasts are microorganisms that are widely distributed and naturally coexist in humans. The prevalence of candida infections, especially in patients with impaired immune systems, has been significant and increasingly challenging over the past three decades [11]. Different strains of Candida are known to cause infections. Recent epidemiological studies have shown that drug-resistant species of Candida, like C. glabrata, C. krusei, C. tropicalis, and C. parapsilosis, are gradually replaced $C$. albicans in diseases ${ }^{[12]}$. Due to the spread of fungal infections and the increase in the use of antifungal drugs such as azoles, a significant increase in the resistance of Candida species to antifungal compounds is expected ${ }^{[13]}$. 1, 3, 4-oxadiazole compounds are one of the 4 subsets of oxadiazoles. A ring contains one oxygen atom and two nitrogen atoms in a five-membered ring. Among the ring compounds, 1, 3, 4-oxadiazole is a main component suitable for the production of new drugs ${ }^{[14]}$. Various 1, 3, 4-oxadiazole derivatives have been shown to have antimicrobial ${ }^{[15]}$, antifungal ${ }^{[16]}$, anticancer ${ }^{[17]}$, and etc. ${ }^{[18]}$ properties so far. In our previous study, some of the structures of these compounds were synthesized and shown to have desirable antibacterial properties against Gram-positive samples [19]. In addition, due to the high reactivity of the main ring containing different functional groups, different functional groups could be synthesized, and their biological properties could be investigated ${ }^{[20]}$.

Objectives: As the synthesis and evaluation of antibacterial and antifungal activities of the new 1, 3, 4-oxadiazole derivatives were 
an important part of this research program [21]; herein, antibacterial and antifungal activities of 1, 3, 4-oxadiazole derivatives containing tolyl, phenyl, dimethylphenyl, aniline, naphthalene, and methoxyphenyl groups were evaluated against $S$. mutans PTCC1683, E. faecalis PTCC1778, P. volgaris PTCC1861, N. meningitidis PTCC1507, C. glabrata PTCC5297, and C. krusei PTCC5295. All organic solvents used in this study were new and different from those used in other studies; the one-step method of synthesizing new derivatives was different too.

\section{Materials and Methods}

This research was conduct in the microbiology laboratory of Islamic Azad University, Tehran branch in 2020. Starting materials, solvents, and culture environments (Nutrient agar/broth, Sabouraud dextrose agar/broth) were obtained from Merck, Germany and used moving forward without any more filtration. The infrared spectrum was measured by a Shimadzu IR-460 spectrometer. Nuclear magnetic resonance (NMR) spectrum was obtained by a Bruker DRX-300 AVANCE spectrometer $\left({ }^{1} \mathrm{H}\right.$ NMR at $300 \mathrm{~Hz},{ }^{13} \mathrm{C} \mathrm{NMR}$ at $75 \mathrm{~Hz}$ ) in acetone. Chromatography columns were prepared using silica gel powder (Merck, Germany). Gas Chromatography-Mass Spectrometry spectra were obtained by Shimadzu triplequad GCMS-TQ8050 NX. All bacterial and fungal strains were prepared from the Iranian Industrial Microorganisms Collection Center (Lyophilized). Microbiological tests were

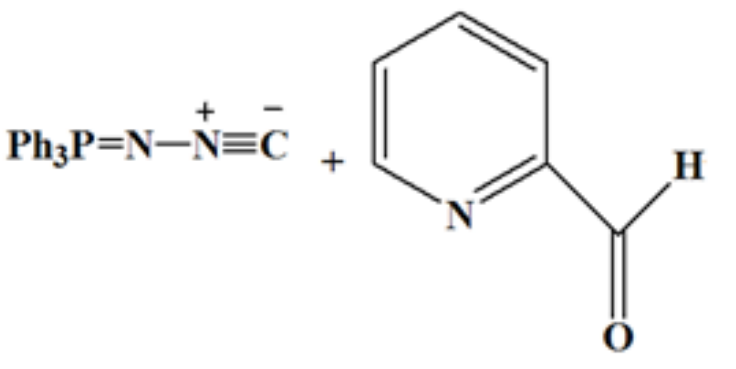

Figure 1) Single-stage synthesis of 1, 3, 4-oxadiazole performed using a Memmert- INC153T2T3 incubator.

Chemistry: 1, 3, 4-oxadiazole compounds were synthesized using a single-stage high yield method (Figure 1). The chemical structure of all the synthesized compounds was investigated using IR spectroscopy, H-NMR, C-NMR, and GCMass.

Single-stage method was performed as follows:

1.First,(N-Isocyanimino)triphenylphosphorane (1mmol, $0.3 \mathrm{~g})$ wasdissolvedindichloromethane (7 mL).

2- In the next step, p-tolyl (4a), m-tolyl (4b), phenyl (4c), dimethyl-phenyl (4d), aniline(4e), naphthalene (4f), and methoxyphenyl $(4 \mathrm{~g})(1 \mathrm{mmoL})$ were added to the previous solution (Table 1, Figure 1) ${ }^{[19]}$. The final solution was stirred for 24 hrs by a magnetic stirrer at $37^{\circ} \mathrm{C}$. The solvent was picked up by vaporization, and the viscous residue was purified by flash column chromatography (silica gel powder: petroleum ether-ethyl acetate (5:1) ${ }^{[22]}$. Infrared, nuclear magnetic resonance, and gas chromatography analysis showed that there was no side product (Figure 2).

Table1) Functional groups

\begin{tabular}{cc}
\hline $\mathbf{4 a}$ & Para-tolyl \\
\hline $\mathbf{4 b}$ & Meta-tolyl \\
\hline $\mathbf{4 c}$ & Phenyl \\
$\mathbf{4 d}$ & Dimethyl-phenyl \\
$\mathbf{4 e}$ & Aniline \\
$\mathbf{4 f}$ & Naphthalene \\
$\mathbf{4 g}$ & Methoxy-phenyl \\
\hline
\end{tabular}

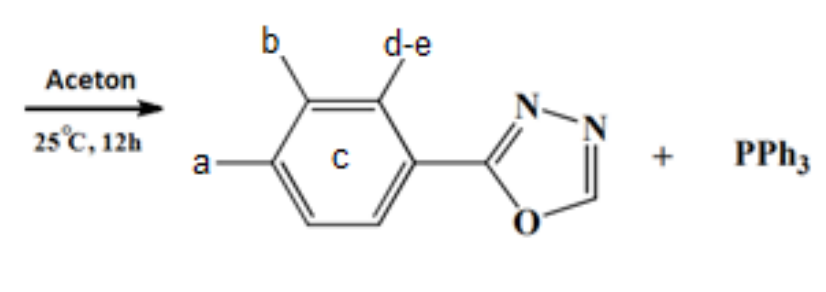


Preparation of the compounds with intended concentrations: Dimethyl sulfoxide (99\%) (DMSO) was used to dissolve all the compounds. Initially, a concentration of 0.5 $\mathrm{mg} / \mathrm{mL}$ was prepared from the powders of the synthesized compounds (1:9 ratio). Afterwards, they were kept at $-18^{\circ} \mathrm{C}$ in sterile test tubes until the tests were performed.

Antibacterial activity: Agar well diffusion (Inhibition Zone), MIC (Minimum Inhibitory Concentration), and MBC (Minimum Bactericidal Concentration)/MFC (Minimum Fungicidal Concentration) methods were used to evaluate antibacterial and antifungal properties of the new synthesized compounds. All antibacterial tests were conducted according to CLSI ${ }^{[23]}$.

\section{Preparation of bacterial and fungal} suspension: The lipophilic ampoules containing S. mutans, E. faecalis, P. volgaris, and $N$. meningitides strains were first opened under sterile conditions and transferred to the nutrient broth culture medium and incubated for 24 hours at $37^{\circ} \mathrm{C}$. Also, for fungi samples, the ampoules containing C. glabrata and $C$. krusei strains were first opened under sterile conditions and transferred to the sabouraud dextrose broth and incubated for 24 hours at $37^{\circ} \mathrm{C}$. Using a sampler, $0.5 \mathrm{~mL}$ of 24 -hour culture of microbial suspension was transferred to a tube containing sterile nutrient broth, and then the turbidity of the microbial suspension was visually compared to the McFarland standard set with a spectrophotometer at 625 $\mathrm{nm}$ and absorption rate of $1.5 \times 10^{8} \mathrm{CFU} / \mathrm{mL}$. For bacterial strains, the nutrient agar culture medium was applied for agar well diffusion test, and the nutrient broth culture medium was used to test the dilution in the tubes. For fungi strains, the sabouraud dextrose agar culture medium was used for agar well diffusion test, and sabouraud dextrose broth culture medium was used to test the dilution in the tubes ${ }^{[23]}$. Agar well diffusion method: To perform this experiment, wells of $5 \mathrm{~mm}$ in diameter were created by a sterile pipette in NA culture media containing cultured bacterial suspension as well as in SDA culture media containing cultured fungal suspension. The wells were then filled with the synthesized compounds (4a-g) and put inside the incubator for 24 hours at $37{ }^{\circ} \mathrm{C}$. It is worth noting that all the steps were done near the flame and in a sterile environment [19]. This experiment was performed in triplicate, and the average results were reported.

Broth dilution method: In the next stage, antibacterial and antifungal activities of the compounds were appraised by broth dilution method. The goal of this method is to characterize the minimum concentration of an antimicrobial agent that, under specific situation, is able to prevent the visible growth of the tested organisms which are thought-out by the lack of darknessin abrothmedium. Minimuminhibitory concentration (MIC) is used in order to specify the capacity of an organism against antibiotics and new antibacterial effects. In this research, sterile glass test tubes containing nutrient broth were used. About $10 \mu \mathrm{L}$ of inoculum containing $1.5 \times 10^{-9} \mathrm{CFU} / \mathrm{mL}$ of tested microorganism was added to each test tube. The minimum inhibitory concentration of the tested compounds was between 1000-1.95 $\mu \mathrm{g} / \mathrm{mL}$. For bacteria, minimum bactericidal concentration (MBC) was determined by sub culturing of the test tubes on NA media with no antibacterial factor. For fungi, minimum fungicidal concentration (MFC) was determined by sub culturing of the test tubes on SDA media with no antifungal factor ${ }^{[24]}$.

Statistical methods: All the inhibition zones diameters obtained in three repetitions were reported as the mean \pm standard deviation. SPSS statistical software Version 22 was used for data analysis.

\section{Findings}

Chemistry: Infrared, C-NMR, H-NMR, and GC-mass spectra of all the compounds were obtained (Figure 2). 


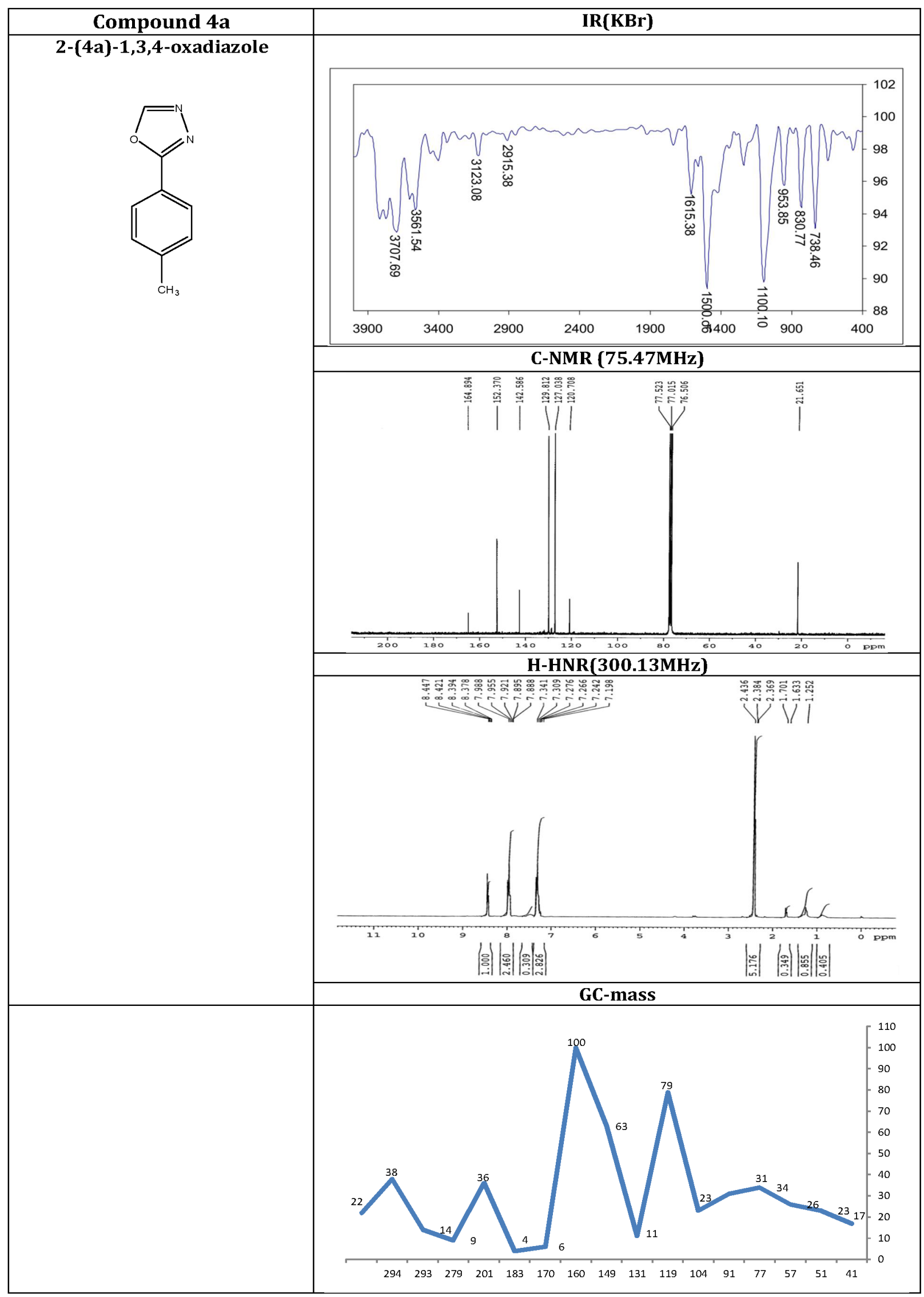

Figure 2) Structural and spectral information of the new synthesized derivatives of 1, 3, 4-oxadiazole 


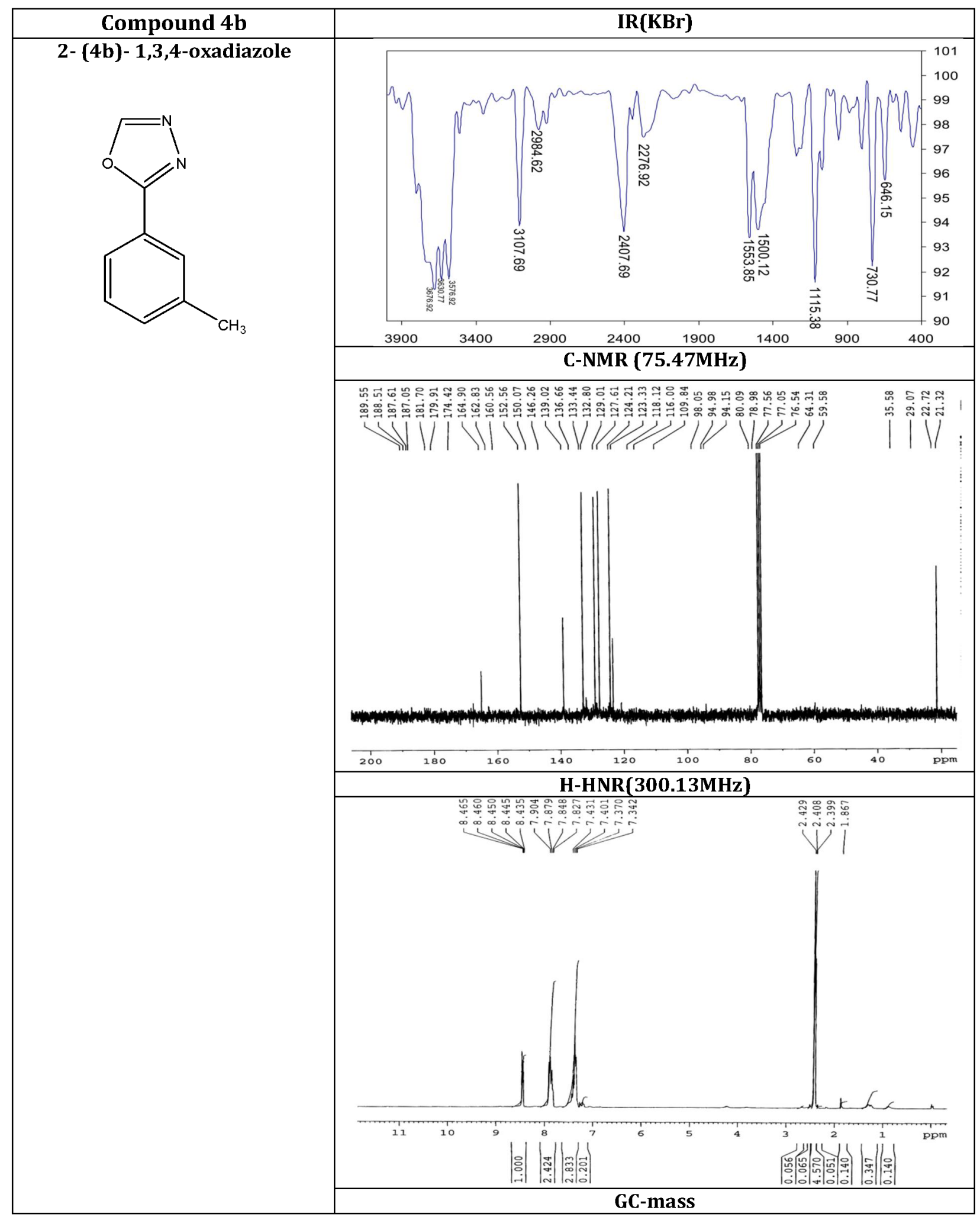

Figure 2) continued 


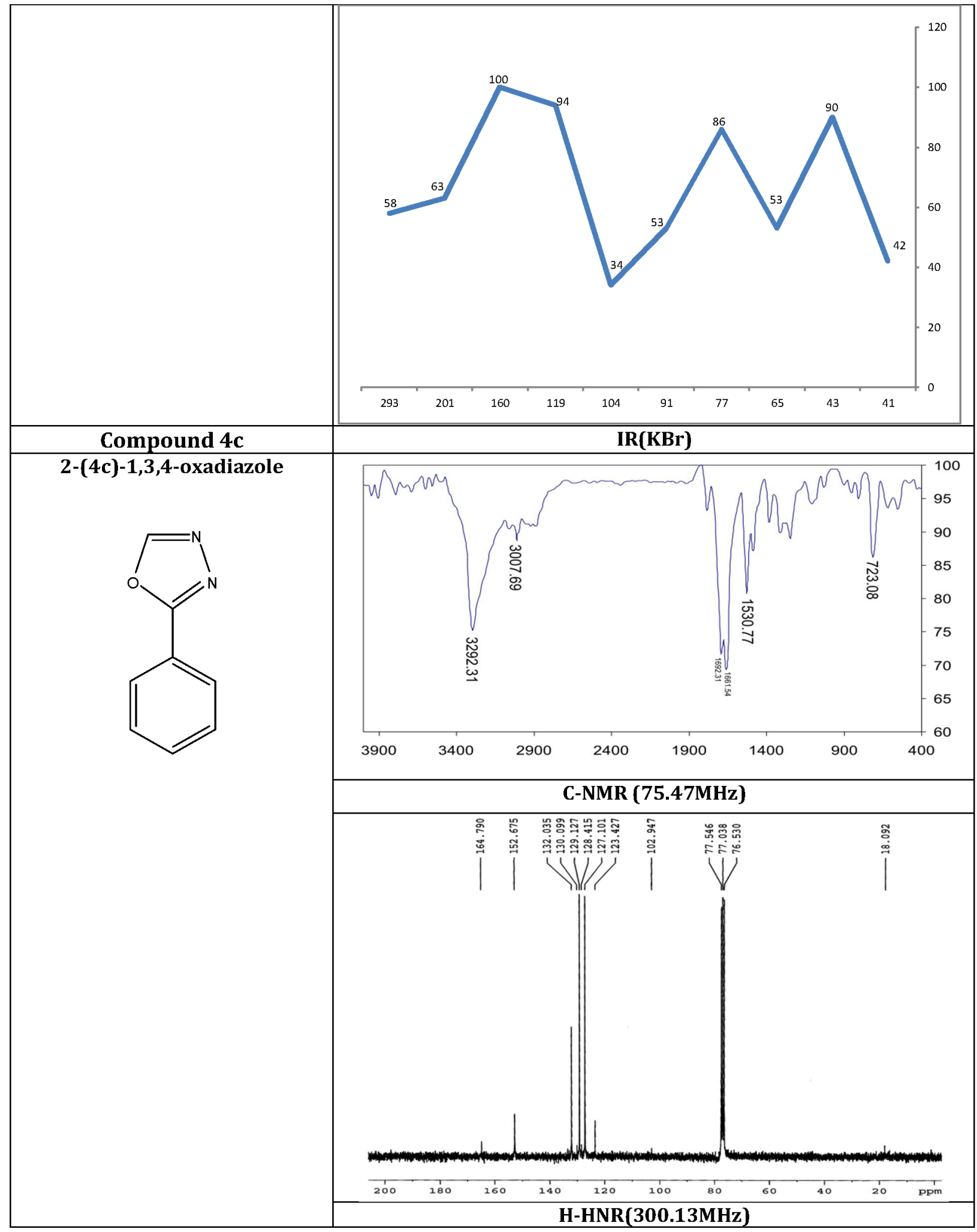

Figure 2) continued 


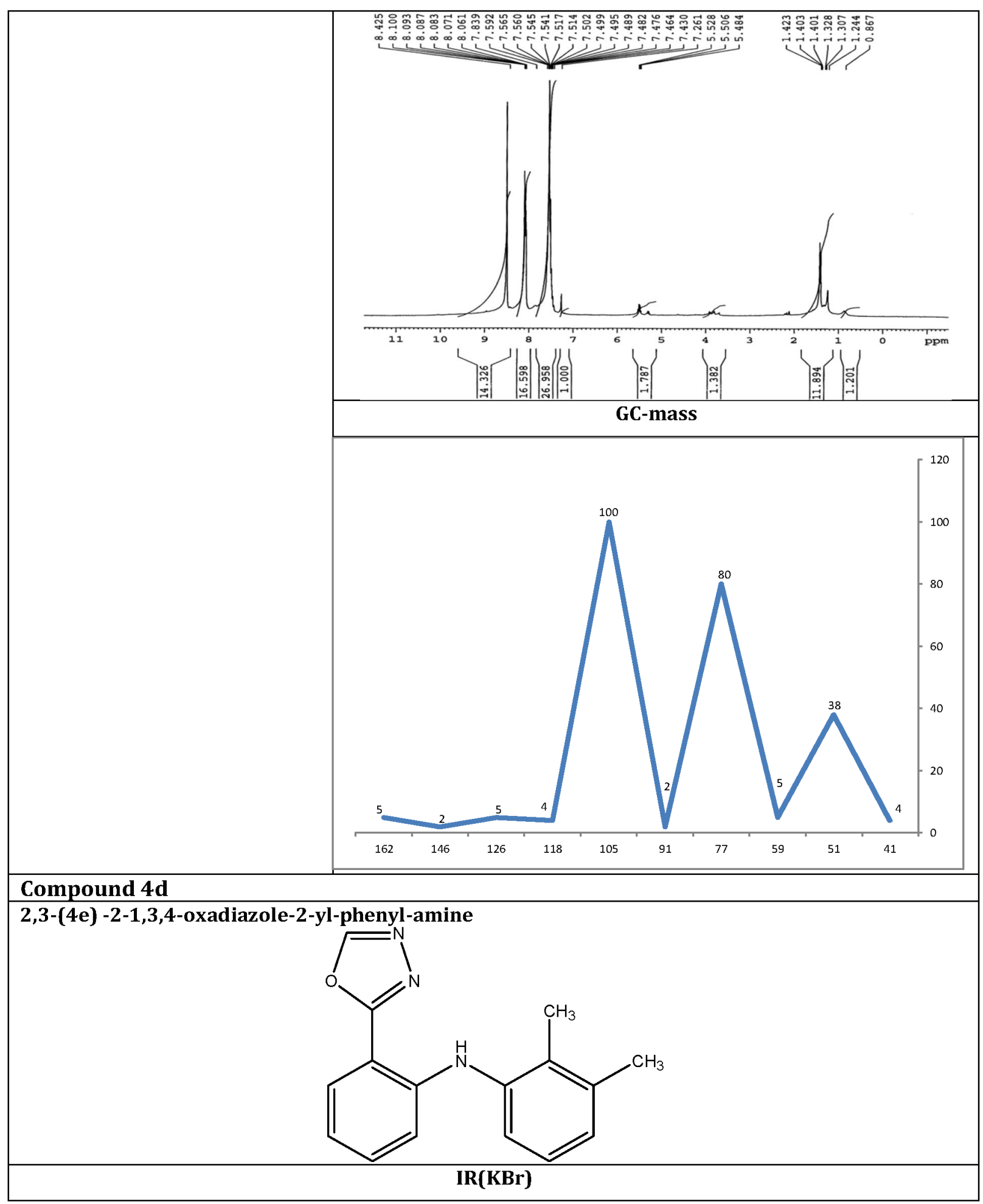

Figure 2) continued 


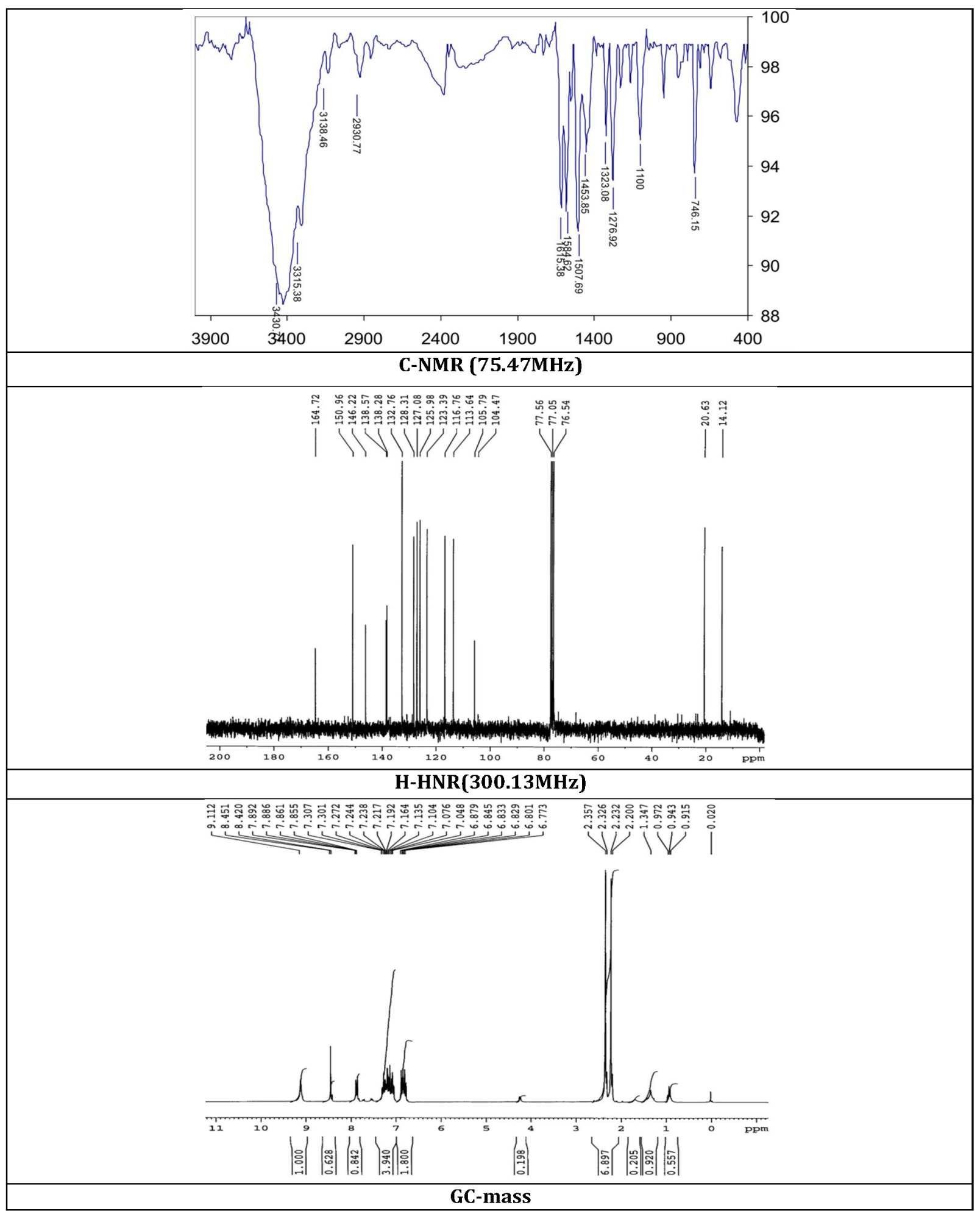

Figure 2) continued 


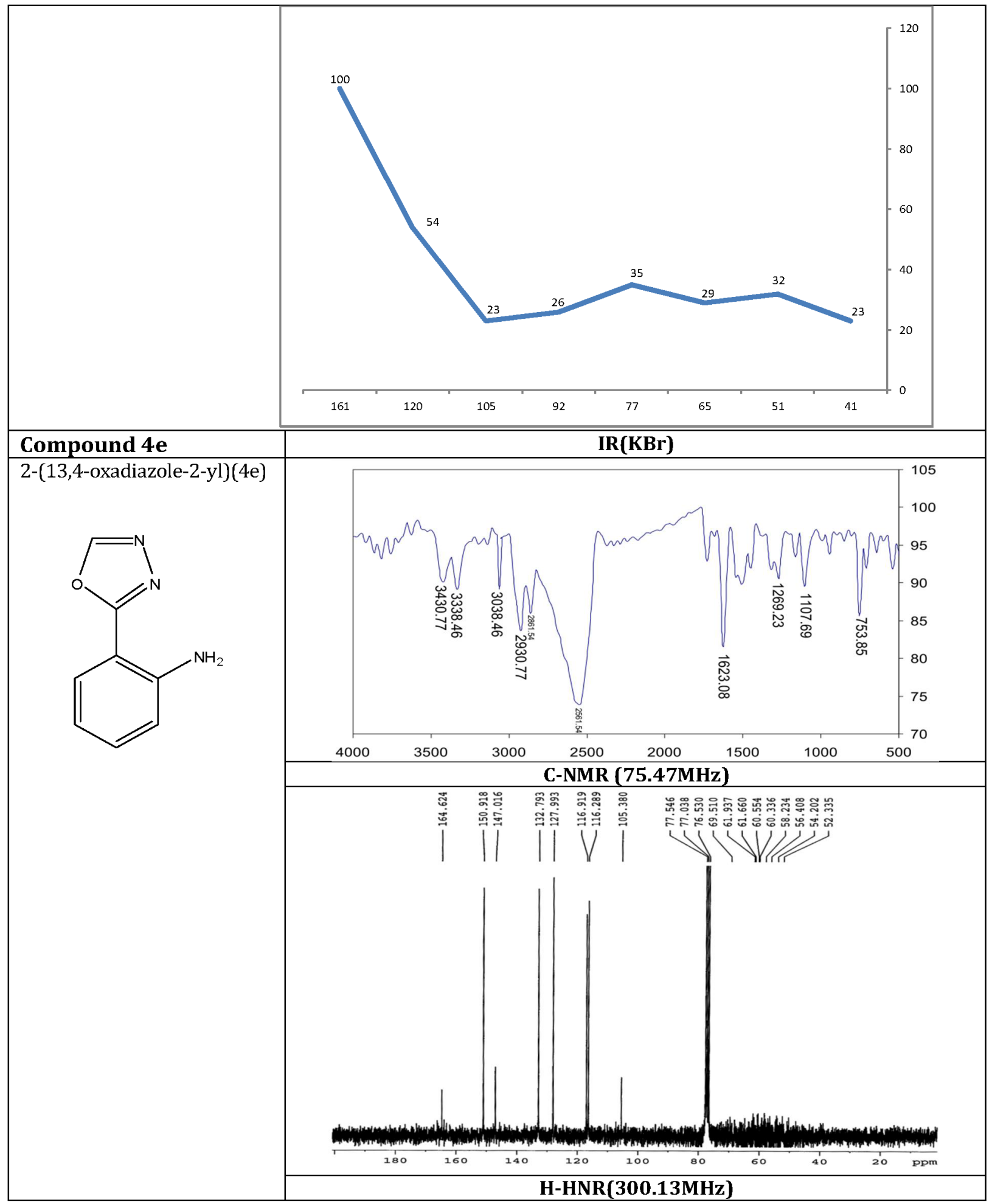

Figure 2) continued 


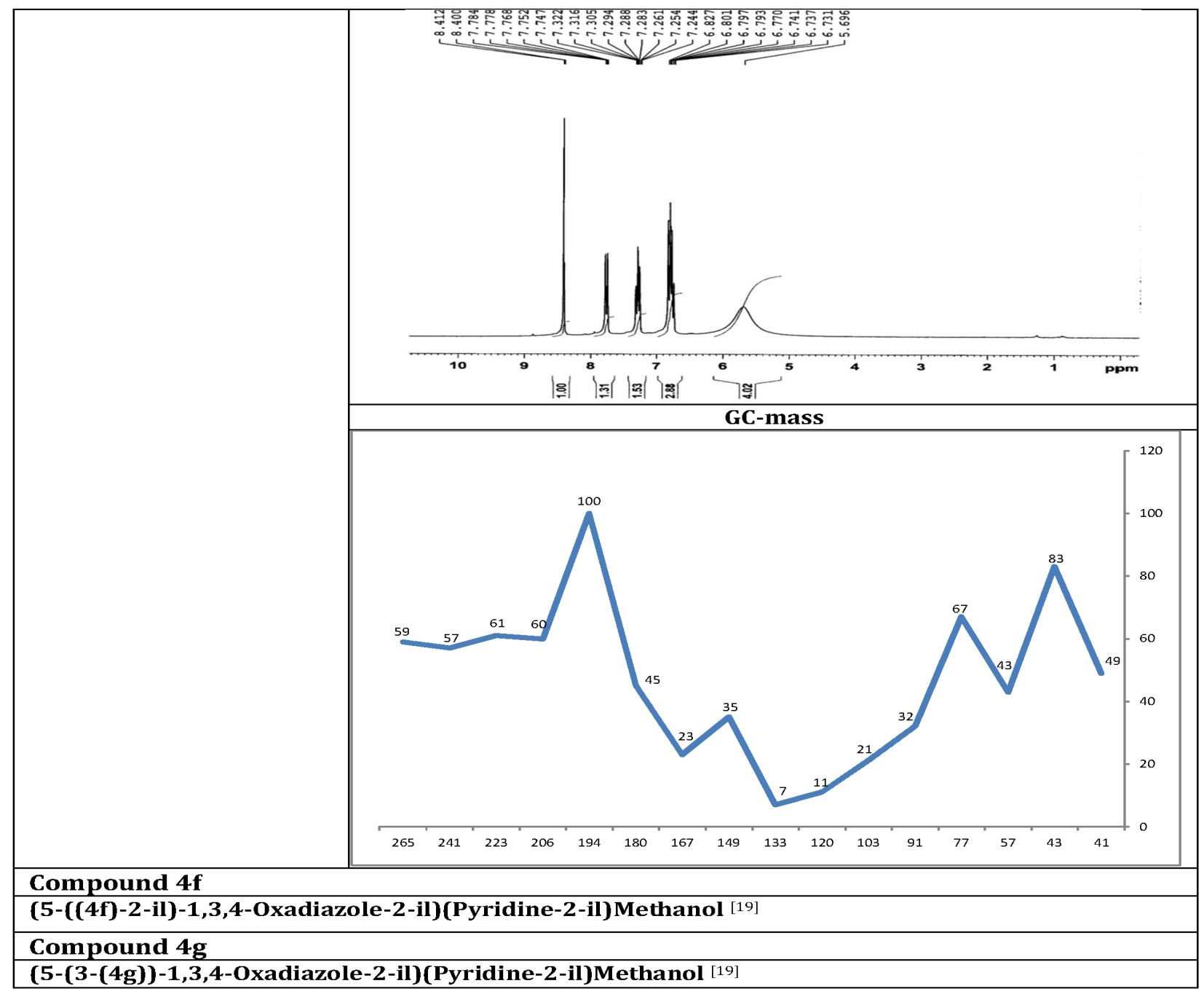

Figure 2) continued

\section{Determination of the in vitro antibacterial} and antifungal activities: Antibacterial and antifungal activities of the prepared 13, 4-oxadiazole derivatives (4a-4g) moieties were evaluated in terms of their structure (Figure 2). The inhibition zones diameters of the synthesized compounds against the tested bacteria and fungi are presented in Table 2 and 3. As shown in Table 2, the compound $4 \mathrm{~d}$ showed high antibacterial activity against $S$. mutans with $\mathrm{IZ}=12.66 \pm 0.5$ $\mathrm{mm}, \mathrm{MIC}=500 \mathrm{mg} / \mathrm{mL}$, and $\mathrm{MBC}=1000$ $\mathrm{mg} / \mathrm{mL}$ and against $N$. meningitidis with $\mathrm{IZ}=23.33 \pm 1.15 \mathrm{~mm}, \mathrm{MIC}=500 \mathrm{mg} / \mathrm{mL}$, and $\mathrm{MBC}=1000 \mathrm{mg} / \mathrm{mL}$; also, the compound $4 \mathrm{~g}$ showed high antibacterial activity against $E$. faecalis with $\mathrm{IZ}=55.66 \pm 0.5 \mathrm{~mm}, \mathrm{MIC}=31.25$ $\mathrm{mg} / \mathrm{mL}$, and $\mathrm{MBC}=62.50 \mathrm{mg} / \mathrm{mL}$, and the compound $4 \mathrm{~b}$ showed high antibacterial activity against $P$. volgaris with $\mathrm{IZ}=19.66 \pm 0.5$ $\mathrm{mm}, \mathrm{MIC}=500 \mathrm{mg} / \mathrm{mL}$, and $\mathrm{MBC}=500 \mathrm{mg} /$ $\mathrm{mL}$. As shown in Table 3, the compound $4 \mathrm{~b}$ showed high antifungal activity against $C$. glabrata with $\mathrm{IZ}=12.33 \pm 0.5 \mathrm{~mm}, \mathrm{MIC}=1000$ $\mathrm{mg} / \mathrm{mL}$, and $\mathrm{MFC}=1000 \mathrm{mg} / \mathrm{mL}$, and against C. krusei with IZ=13.33 $\pm 0.5 \mathrm{~mm}, \mathrm{MIC}=1000$ $\mathrm{mg} / \mathrm{mL}$, and $\mathrm{MFC}=1000 \mathrm{mg} / \mathrm{mL}$. As shown in Figure 5, the significant results obtained in this study indicated that most of the synthesized compounds performed very well against the Gram-positive samples (E. faecalis); so that the compound $4 \mathrm{~g}$ showed acceptable inhibitory effects with high IZ, MIC, and MBC. 
Table 2) Antibacterial activity of 1, 3, 4-oxadiazol derivatives, evaluated by Agar well diffusion (IZ), MIC, and MBC methods $(0.5 \mathrm{mg} / \mathrm{mL})$. \pm : Averaged three times. -: No activity

\begin{tabular}{|c|c|c|c|c|c|c|c|c|c|c|c|c|}
\hline \multicolumn{12}{|c|}{ Microorganism } & \multirow{3}{*}{ 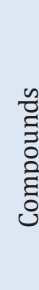 } \\
\hline \multicolumn{3}{|c|}{$\begin{array}{l}\text { Neisseria meningitidis } \\
\text { PTCC1507 }\end{array}$} & \multicolumn{3}{|c|}{$\begin{array}{l}\text { Proteus volgaris } \\
\text { PTCC1861 }\end{array}$} & \multicolumn{3}{|c|}{$\begin{array}{c}\text { Enterococcus faecalis } \\
\text { PTCC1778 }\end{array}$} & \multicolumn{3}{|c|}{$\begin{array}{c}\text { Streptococcus mutans } \\
\text { PTCC1683 }\end{array}$} & \\
\hline MBC & MIC & IZ & MBC & MIC & IZ & MBC & MIC & IZ & MBC & MIC & IZ & \\
\hline- & - & $9.33 \pm 0.5$ & 1000 & 500 & $19.33 \pm 1.15$ & - & - & - & - & - & $10.66 \pm 0.5$ & $4 a$ \\
\hline- & - & $19.66 \pm 0.5$ & 500 & 500 & $19.66 \pm 0.5$ & 1000 & 500 & $29.33 \pm 0.5$ & - & - & - & $4 b$ \\
\hline- & - & $12.66 \pm 0.5$ & - & - & $13.33 \pm 1.15$ & - & - & $9.33 \pm 0.5$ & - & - & $10.33 \pm 0.5$ & $4 c$ \\
\hline 1000 & 500 & $23.33 \pm 1.15$ & - & - & $12.66 \pm 1.15$ & 1000 & 500 & $23.33 \pm 1.15$ & 1000 & 500 & $12.66 \pm 0.5$ & $4 d$ \\
\hline- & - & $15.66 \pm 0.5$ & - & - & $11.66 \pm 0.5$ & 500 & 500 & $24.66 \pm 1.15$ & - & - & $11.00 \pm 0.5$ & $4 \mathrm{e}$ \\
\hline- & - & $10.33 \pm 0.5$ & - & - & $14.33 \pm 1.15$ & 500 & 125 & $39.33 \pm 1.15$ & - & - & $10.33 \pm 0.5$ & $4 \mathrm{f}$ \\
\hline- & - & $9.33 \pm 0.5$ & - & - & $12.33 \pm 1.15$ & 62.50 & 31.25 & $55.66 \pm 0.5$ & - & - & $11.33 \pm 0.5$ & $4 \mathrm{~g}$ \\
\hline
\end{tabular}

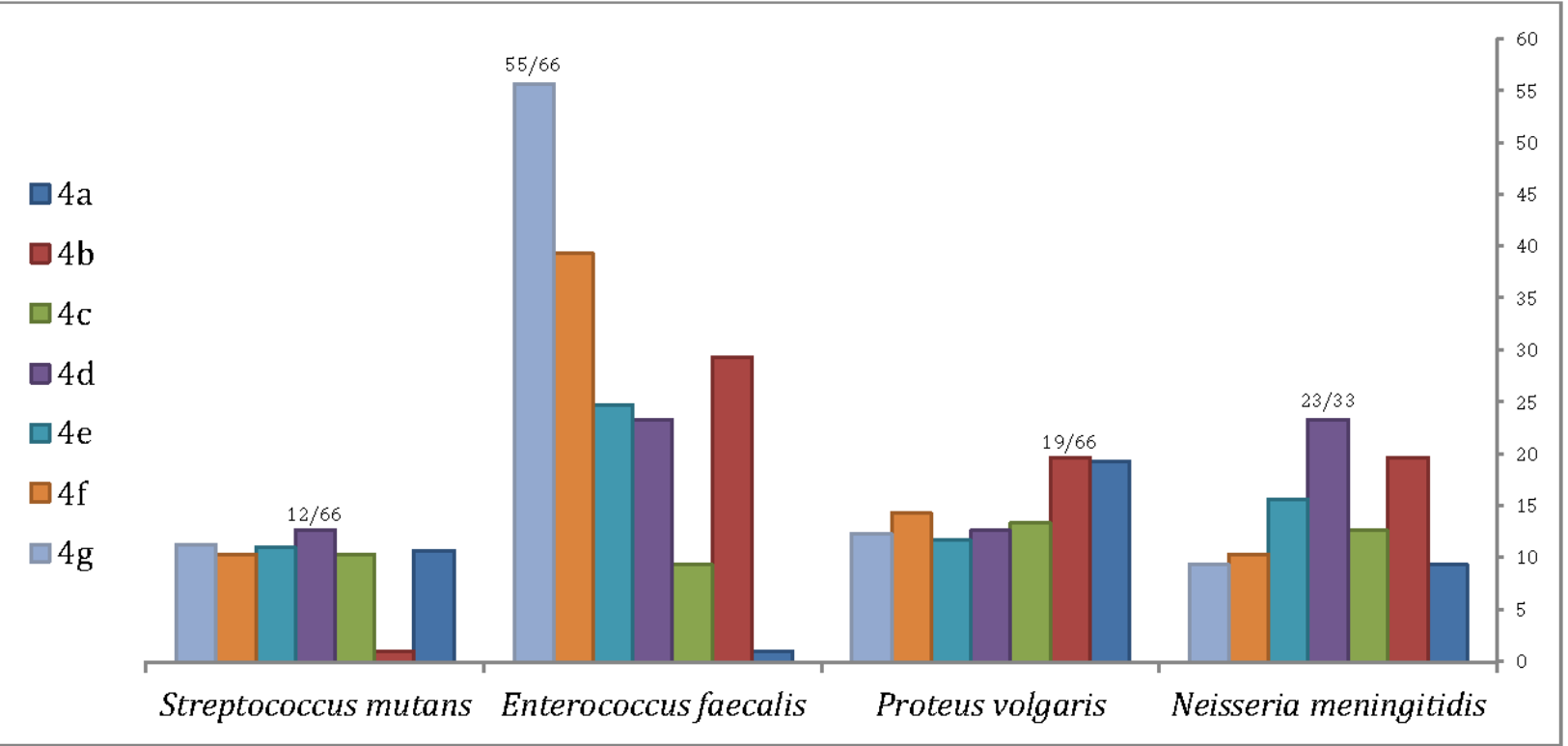

Figure 3) Comparison of the inhibition zone diameters of the compounds against the bacterial samples 
Table 3) Antifungal activity of 1, 3, 4-oxadiazol derivatives, evaluated by Agar well diffusion (IZ), MIC, and MFC methods $(0.5 \mathrm{mg} / \mathrm{mL}) . \pm$ : Averaged three times. - : No activity

\begin{tabular}{|c|c|c|c|c|c|c|}
\hline \multicolumn{6}{|c|}{ Microorganism } & \multirow{3}{*}{ Compounds } \\
\hline \multicolumn{3}{|c|}{$\begin{array}{l}\text { Candida krusei } \\
\text { PTCC5295 }\end{array}$} & \multicolumn{3}{|c|}{$\begin{array}{c}\text { Candida glabrata } \\
\text { PTCC5297 }\end{array}$} & \\
\hline $\mathrm{MFC}$ & MIC & IZ & MFC & MIC & IZ & \\
\hline - & - & $11.33 \pm 0.5$ & - & - & - & $4 a$ \\
\hline 1000 & 1000 & $13.33 \pm 0.5$ & 1000 & 1000 & $12.33 \pm 0.5$ & $4 b$ \\
\hline- & - & $11.66 \pm 0.5$ & - & - & - & $4 c$ \\
\hline- & - & $11.66 \pm 0.5$ & - & - & $11.66 \pm 0.5$ & $4 d$ \\
\hline - & - & $11.33 \pm 0.5$ & - & - & $11.66 \pm 0.5$ & $4 e$ \\
\hline - & - & $11.66 \pm 0.5$ & - & - & - & $4 f$ \\
\hline- & - & - & - & - & $11.66 \pm 0.5$ & $4 \mathrm{~g}$ \\
\hline
\end{tabular}

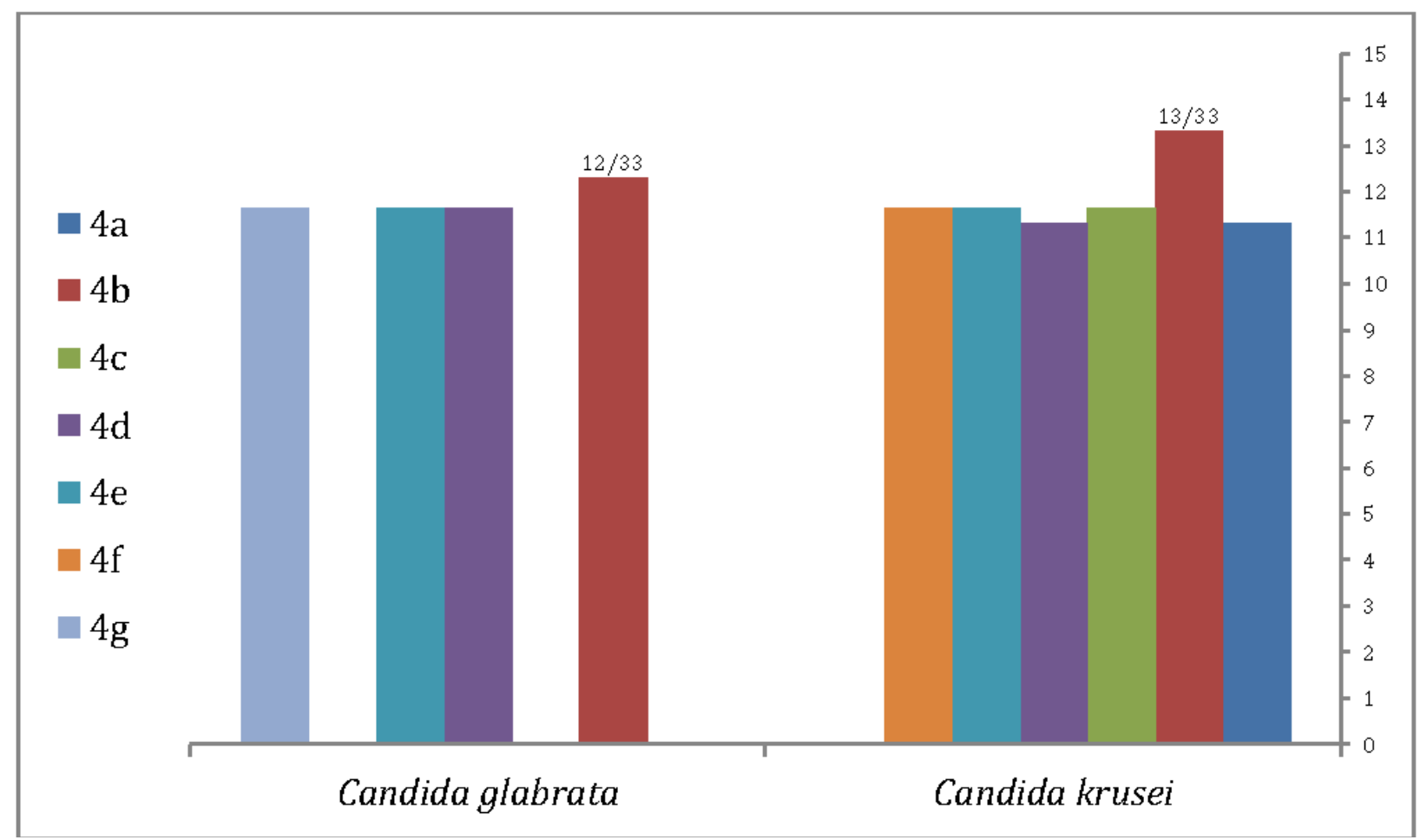

Figure 4) Comparison of the inhibition zone diameters of the compounds against the fungal samples 


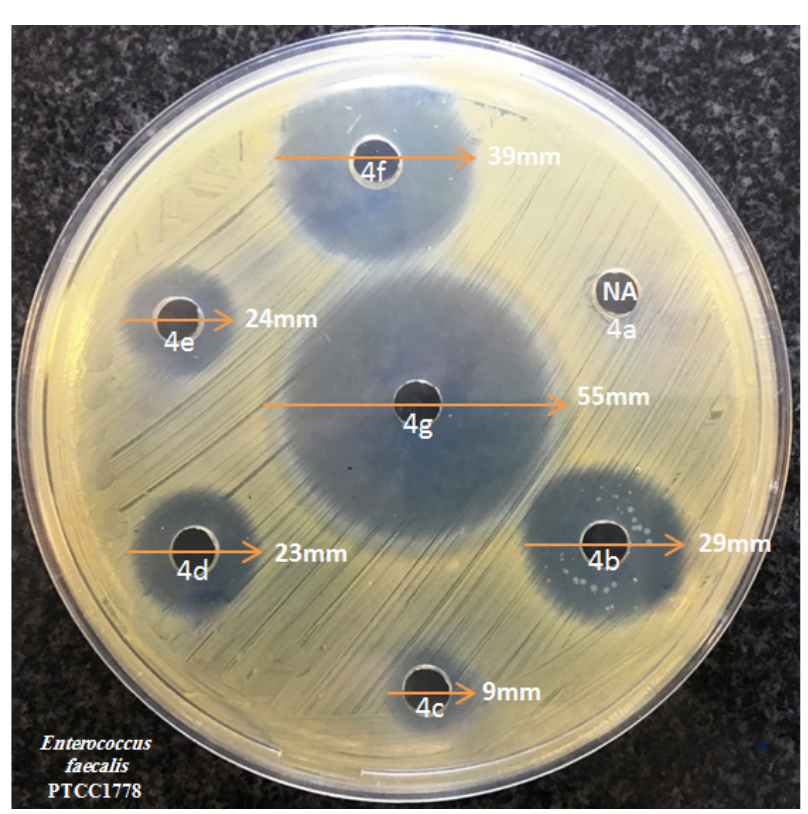

Figure 5) Inhibition zone of the compounds against Enterococcus faecalis at $0.5 \mathrm{mg} / \mathrm{mL}$ concentration

\section{Discussion}

Antimicrobial resistance has the potential to influence individuals at any stage of life, healthcare system, veterinary, and horticulture businesses, making it one of the most important public health problems in the world. Each year in the United States, at least 2.8 million individuals are infected by antibiotic-resistant microbes or parasites, and more than 35,000 individuals die as a result. No one could totally maintain a safe strategic distance from the risk of diseases, but a few individuals are at higher risk than others. If antimicrobial agents lose their efficiency, at this point the healthcare system loses the capacity to treat contaminations and control public health risks ${ }^{[25]}$. One way to solve this crisis is to find new antimicrobial compounds to replace current antibiotics. 1, 3, 4-oxadiazole derivatives are novel antibacterial compounds, which are good replacements for a few antibacterial drugs. The objective of this study was to evaluate in vitro antibacterial and antifungal activities of 1,3,4-oxadiazole derivatives against some pathogenic bacteria and fungi. In recent years, a number of new 1, 3, 4-oxadiazole analogues have been introduced as antimicrobial agents ${ }^{[26]}$. The latest study on 1, 3, 4-oxadiazole with methoxyphenyl group reported that this group in 4, 3, 1-oxadiazole structure has a good antibacterial effect against Gram-positive and Gram-negative bacteria ${ }^{[27]}$, which is in line with the present study results. In the present investigation, (5-(3-methoxyphenyle)-1, 3, 4-oxadiazole2-il) (pyridine-2-il) methanol (4g) was the most active antibacterial compound with inhibition zone diameters similar or comparable to that of the reference drug. This may be due to the presence of methoxyphenyl with (pyridine-2-il) and methanol together. These findings are in line with the findings of other studies by Guo et al. (2019) [28], Bhaumik et al. (2019) [18], and Tresse et al. (2019) ${ }^{[29]}$ on 1, 3, 4-oxadiazole derivatives. In this study, all the derivatives of 1, 3, 4-oxadiazole were synthesized for the first time. They showed inhibitory properties against Gram positive and Gram negative bacteria; however, they did not show inhibitory properties against fungal strains except $4 \mathrm{~b}$. This study showed more promising results than previous studies to introduce these structures as antibacterial agents. In the present study, the presence of tolyl, phenyl, and naphthalene rings caused a considerable decrease in the antifungal potential of the compounds, but they were able to increase antibacterial properties. Therefore, it could be inferred that the presence of these groups in similar structures, especially the methoxy-phenyl group, enhances the antimicrobial activity.

\section{Conclusion}

In this study, 1, 3, 4-oxadiazole derivatives exhibited a narrow-spectrum antibacterial activity, especially against E. faecalis. The obtained results showed that dimethylphenyl and 3-methoxyphenyl could 
be considered as a useful structure for the possible development of new antibacterial drugs. Also, tolyl group could be considered as a useful structure for the possible development of new antifungal drugs. Further studies are required to assess the cytotoxicity of such compounds.

Acknowledgments: The authors would like to thank from the Islamic Azad University, Tehran Branch for its financial support.

Ethical Permissions: There are no ethical permissions.

Conflicts of Interests: There are no conflicts of interest.

Author Contributions: Conceptualization: AS, YSA; Data curation and formal analysis: NZA, AS, YSA; Investigation: YSA; Methodology and project administration: YSA, NZA; Supervision: NZA, AS, YSA; Validation: YSA, NZA; Writing of original draft: YSA; Writing, reviewing, and editing: YSA.

Fundings: This research was the continuation of the author's master's thesis (Code: 10330507951009), done at the Islamic Azad University, Central Tehran Branch (PhD courses).

Consent to participate: Not applicable.

\section{References}

1. White NJ. Antimalarial drug resistance. J Clin Invest. 2004; 113(8):1084-92.

2. Antony HA, Parija SC. Antimalarial drug resistance: An overview. Trop Parasitol. 2016; 6(1):30-41.

3. Lemos JA, Palmer SR, Zeng L, Wen ZT, Kajfasz JK, Freires IA, et al. The biology of Streptococcus mutans. In: Fischetti VA, Novick RP, Ferretti JJ, Portnoy DA, Braunstein M, Rood JI, editors. Gram-positive pathogens. 3th ed. Wiley; 2019, pp. 435-48.

4. Jafri H, Khan MS, Ahmad I. In vitro efficacy of eugenol in inhibiting single and mixed-biofilms of drug-resistant strains of Candida albicans and Streptococcus mutans. Phytomedicine. 2019; 54:206-13.

5. Dahl A, Iversen $\mathrm{K}$, Tonder $\mathrm{N}$, Hoest $\mathrm{N}$, Arpi $M$, Dalsgaard M, et al. Prevalence of infective endocarditis in Enterococcus faecalis bacteremia. J Am Coll Cardiol. 2019; 74(2):193-201.

6. Davis E, Hicks L, Ali I, Salzman E, Wang J, Snitkin E, et al. Epidemiology of vancomycin-resistant Enterococcus faecium and Enterococcus faecalis colonization in nursing facilities. In Open forum infectious diseases. US: Oxford University Press; 2020 (Vol. 7, No. 1, p. ofz553).

7. Keppler-Noreuil KM, Sapp JC, Lindhurst MJ, Darling TN, Burton-Akright J, Bagheri $M$, et al. Pharmacodynamic study of miransertib in individuals with Proteus syndrome. Am J Hum Genet. 2019; 104(3):484-91.

8. Bontron S, Poirel L, Kieffer N, Savov E, Trifonova A, Todorova I, et al. Increased resistance to carbapenems in Proteus mirabilis mediated by amplification of the bla VIM-1-carrying and IS 26-associated Class 1 Integron. Microb Drug Resist. 2019; 25(5):663-7.

9. Caugant DA, Brynildsrud OB. Neisseria meningitidis: Using genomics to understand diversity, evolution, and pathogenesis. Nat Rev Microbiol. 2019; 18(4):84-96.

10. McNamara LA, Potts C, Blain AE, Retchless AC, Reese N, Swint S, et al. Detection of ciprofloxacinresistant, $\beta$-lactamase-producing Neisseria meningitidis Serogroup $Y$ isolates-United States, 2019-2020. Morb Mortal Wkly Rep. 2020; 69(24):735-9.

11. Kullberg BJ, Viscoli C, Pappas PG, Vazquez J, Ostrosky-Zeichner L, Rotstein C, et al. Isavuconazole versus caspofungin in the treatment of candidemia and other invasive candida infections: the ACTIVE trial. Clin Infect Dis. 2019; 68(12):1981-9.

12. Yeh SJ, Yeh CC, Lan CY, Chen BS. Investigating common pathogenic mechanisms between homo sapiens and different strains of Candida albicans for drug design: Systems biology approach via two-sided NGS data identification. Toxins. 2019; 11(2):119.

13. Pristov KE, Ghannoum MA. Resistance of Candida to azoles and echinocandins worldwide. Clin Microbiol Infect. 2019; 25(7):792-8.

14. Sarveahrabi Y, Souldozi A, Talebi R. 2-Substituent synthesis of 5-3-methoxyphenyl and 5-4-methoxyphenyl-1, 3, 4-oxadiazoles, 2-Ylpyridine-2-Yl-methanol in positions of 2 and 3 of 1,3,4-oxadiazoles containing halogen and the evaluation of their antibacterial properties. Navid No. 2020; 22(72):1-3.

15. Bitla S, Sagurthi SR, Dhanavath R, Reddy PM, Birudaraju S, Gayatri AA, et al. Design and synthesis of triazole conjugated novel 2, 5-diaryl substituted 1, 3, 4-oxadiazoles as potential antimicrobial and anti-fungal agents. J Mol Struct. 2020; 1220:128705. 
16. Maslat AO, Abussaud M, Tashtoush H, AL-Talib M. Synthesis, antibacterial, antifungal, and genotoxic activity of bis-1, 3, 4-oxadiazole derivatives. Pol J Pharmacol. 2002; 54(1):55-60.

17. Ahsan MJ, Choupra A, Sharma RK, Jadav SS, Padmaja P, Hassan M, et al. Rationale design, synthesis, cytotoxicity evaluation, and molecular docking studies of 1, 3, 4-oxadiazole analogues. Anticancer Agent Med Chem. 2018; 18(1):12138.

18. Bhaumik A, Eswaraiah MC, Chakraborty R. Evaluation of antimicrobial profile of some novel 1, 3, 4-oxadiazole derivatives followed by molecular docking against 3G7E bacterial DNA gyrase. J Drug Deliv Ther. 2019; 9(4):438-53.

19. SarveAhrabi Y, Souldozi A, Zarrabi Ahrabi N. In vitro evaluation of antimicrobial properties of some new 1, 3, 4-oxadiazole derivatives against Acinetobacter baumannii. Infect Epidemiol Microbiol. 2020; 6(1):37-49.

20. Rohand T, Ramli Y, Baruah M, Budka J, Das AM. Synthesis, structure elucidation, and antimicrobial properties of new bis-1, 3, 4-oxadiazole derivatives. Pharm Chem J. 2019; $53(2): 150-4$.

21. Shi J, Luo N, Ding M, Bao X. Synthesis, in vitro antibacterial and antifungal evaluation of novel 1, 3, 4-oxadiazole thioether derivatives bearing the 6-fluoroquinazolinylpiperidinyl moiety. Chin Chem Lett. 2020; 31(2):434-8.

22. Souldozi A, Karami S. One-pot three-component reaction for the synthesis of novel series of fully substituted 1, 3, 4-oxadiazole derivatives bearing pyridine moiety. Phosphorus Sulfur Silicon Relat Elem. 2016; 191(6):867-70.

23. Clinical and Laboratory Standards Institute. Supplement M100: Performance standards for antimicrobial susceptibility testing. CLSI; 2017.

24. Lee WB, Fu CY, Chang WH, You HL, Wang CH, Lee $\mathrm{MS}$, et al. A microfluidic device for antimicrobial susceptibility testing based on a broth dilution method. Biosens Bioelectron. 2017; 87:669-78.

25. Lushniak BD. Antibiotic resistance: A public health crisis. Public Health Rep. 2014; 129(4):314-6.

26. Othman AA, Kihel M, Amara S. 1, 3, 4-oxadiazole, 1, 3, 4-thiadiazole, and 1, 2, 4-triazole derivatives as potential antibacterial agents. Arab J Chem. 2019; 12(7):1660-75.

27. Aghekyan AA, Mkryan GG, Panosyan HA, Safaryan AS, Stepanyan HM. Synthesis and antibacterial activity of novel (4-methoxyphenyl)tetrahydropyranyl-substituted 1, 3, 4-oxadiazoles. Russ J Org Chem. 2020; 56:281-6.

28. Guo Y, Xu T, Bao C, Liu Z, Fan J, Yang R, et al. Design and synthesis of new norfloxacin-1,3,4-oxadiazole hybrids as antibacterial agents against methicillinresistant Staphylococcus aureus (MRSA). Eur J Pharm Sci. 2019; 136:104966.

29. Tresse C, Radigue R, Von Borowski RG, Thepaut M, Le HH, Demay F, et al. Synthesis and evaluation of 1, 3, 4-oxadiazole derivatives for development as broad-spectrum antibiotics. Bioorg Med Chem. 2019; 27(21):115097. 